\title{
Dementia care and service systems - a mapping system tested in nine Swedish municipalities
}

\author{
Connie Lethin ${ }^{1,3^{*}}$ (D) Lottie Giertz ${ }^{2}$, Emme-Li Vingare $^{2}$ (D) and Ingalill Rahm Hallberg ${ }^{1}$ (D)
}

\begin{abstract}
Background: In dementia care, it is crucial that the chain of care is adapted to the needs of people with dementia and their informal caregivers throughout the course of the disease. Assessing the existing dementia care system with regard to facilities, availability and utilization may provide useful information for ensuring that the professional dementia care and service system meets the needs of patients and their families from disease onset to end of life.

Methods: The aim of this study was to further develop and test a mapping system, and adapt it to a local context. In addition, the aim was to assess availability and utilization of care activities as well as professional providers' educational level in nine municipalities under the categories of Screening, the diagnostic procedures, and treatment; Outpatient care facilities; Institutional care and Palliative care. This cross-sectional study was conducted in April through May 2015. Data was derived from the health care and social service systems in nine rural and urban municipalities in two counties in Sweden. The mapping system covered seven categories with altogether 56 types of health care and social service activities.
\end{abstract}

Results: The mapping system was found to be reliable with minor adaptations to the context mainly in terms of activities. Availability of care activities was common with low utilization regarding Screening, the diagnostic procedures, and treatment; Outpatient care facilities; Institutional care and Palliative care and dementia trained staff was rare. Availability and utilization of care activities and professionals' educational level was higher concerning screening, the diagnostic procedures and treatment compared with outpatient care facilities, institutional care and palliative care.

Conclusions: The mapping system enables policy makers and professionals to assess and develop health care and social service systems, to be offered proactively and on equal terms to people with dementia and their informal caregivers throughout the course of the disease. The educational level of professionals providing care and services may reveal where, in the chain of care, dementia-specific education for professionals, needs to be developed.

Keywords: Dementia, Chain of care, Screening, Institutional care, Palliative care, Professional care providers, Education

\section{Background}

In dementia care, it is crucial that the chain of care is adapted to the needs of people with dementia and their informal caregivers throughout the course of the disease. Dementia diseases are progressive and individuals at different stages have different needs in terms of professional care and service, including support and knowledge

\footnotetext{
* Correspondence: connie.lethin@med.lu.se

${ }^{1}$ Faculty of Medicine, Department of Health Sciences, Lund University, PO Box 157, 22100 Lund, Sweden

${ }^{3}$ Faculty of Medicine, Department of Clinical Sciences, Clinical Memory

Research Unit, Lund, Sweden

Full list of author information is available at the end of the article
}

transfer to informal caregivers. Currently there is a lack of knowledge about how to best structure health care and social service systems to meet the needs throughout the disease process. A newly developed mapping system to assess dementia care systems was applied at a national level in eight European countries in the RightTimePlaceCare (RTPC) study (No. 2421 53), conducted between 2010 and 2013 [1]. So far, it has not been tested locally in municipalities and counties. Assessing the dementia care system regarding facilities, availability and utilization may be informative and serve to ensure that the professional

(C) The Author(s). 2018 Open Access This article is distributed under the terms of the Creative Commons Attribution 4.0 International License (http://creativecommons.org/licenses/by/4.0/), which permits unrestricted use, distribution, and 
dementia care and service system meets the needs of patients and their families from disease onset to end of life.

With the demographic transition to an ageing population taking place worldwide, more people are developing dementia [2]. The political view in Western societies has been that people should be able to "age in place" [3] i.e. at home, informal caregivers more transferring more responsibility to informal caregivers. Thus, people with dementia will more commonly be cared for at home, with an informal caregiver involved as the main provider of care and services. Dementia diseases progress towards increased dependence in activities of daily living as well as severe communication difficulties, in particular at the later stage of the disease. This may be experienced as being out of control, as well as feelings of uncertainty, and fear of the unknown [4] and thus trigger behavioural problems. People with dementia and their caregivers sometimes experience professionals as mainly reactive to their needs [5], and perceive the dementia care system as fragmented and hard to access $[6,7]$.

This challenges the professional health care and social service system to deliver a continuum of individualized care and support for people with dementia and their informal caregivers $[8,9]$. It needs to include information about available professional care and services, knowledge about how to provide basic care, about the dementia disease and how to understand and meet the needs of the person with dementia, and respite care for both people with dementia and their informal caregivers. Access to formal care, i.e. availability and utilization of health care and social services, is dependent on professionals' and informal caregivers' ability to interact with the accessibility [10] and, in addition, the professionals' educational level.

This study reports on a Swedish project titled, "Living with dementia, care and service systems (LWD)" (No. 2013121), which was inspired by the RTPC study. Instead of taking a national perspective, a local perspective was adopted when applying the study to municipalities, to explore the variation between municipalities and test the mapping system for its applicability in illuminating resources available to people with dementia diseases and their informal caregivers. It is hoped that through the mapping system, the municipalities will be able to critically review and adjust the system to serve people with dementia and their caregivers. The LWD study addresses key issues in dementia care such as the range of care and services, living conditions for people with dementia and informal caregivers, and their quality of life, applying a model based on the one hand, on the process of dementia from early stage to end of life and on the other hand, the type of activities needed to meet the needs of them.
The original mapping system [1] aimed to get a national overview of available and utilized care activities in eight European countries, and covered 50 types of health care and social services (from here on referred to as "care activities") categorized in seven categories throughout the course of the dementia disease. Furthermore, the aim was to explore who professional caregivers educational level according to the International Standard Classification of Education (ISCED) [11] for each care activity. The mapping system was originally developed by researchers from each country, identifying different activities provided by professionals and non-professionals. Agreement on concepts and terminology was worked through, inspired by consensus methods [12].

The original mapping system covered a wide range of different care activities and these were structured into seven care categories: Screening, the diagnostic procedures, and treatment, and Outpatient care facilities. Furthermore, they covered Care at home, Institutional care, Palliative care, Informal caregiving and supportive actions, and Civic organizations. The categories was based on knowledge about needs during the process of dementia. Most of the care activities were in the category Care at home $(n=18)$ and the least range of activities were in the category of Informal caregiving and supportive actions $(n=4)$ [1]. Analysing the Care at home category showed higher availability than utilization [13], and the findings indicated more similarities than differences between the eight European countries. Furthermore, the original study revealed that specialized dementia care and services were sparsely available and even more sparsely utilized [1]. Support for informal caregivers was available but utilized by few and this was consistent for all the countries. Several types of professionals were involved in the care activities, but it was not always clear who was responsible for what [14] and the more personal care required the lower the education of the professionals involved. Those involved in Screening, the diagnostic procedures, and treatment and Outpatient care facilities were educated at a Bachelor's level or higher, while everyday care was provided by professionals, trained at a lower ISCED level or workers with no formal training at all. Professionals specifically trained in dementia care were rare $[14,15]$. In addition, countries with national guidelines seemed more aware of the importance of professionals with specialized dementia education [15].

The rationale behind this study is that testing and developing the mapping system further may be useful for assessing the care activities at the local level, including the structure of the health care and social service systems. Furthermore, it may be useful for describing availability and utilization of health care and social services for people with dementia and their informal caregivers 
and for determining professional providers' educational level. By making the resources available and visible to the staff as well as the informal caregiver and the person with dementia it may be used more efficiently, some activities taken out and others added. Policy makers and professionals may be enabled to develop their health care and social service system. Making the system visible to professionals, they can be more proactive and communicate available care and support to people with dementia and caregivers. This is important to ensure transparency, accessibility, and equal and individualized health care and social services to all citizens regarding dementia care, and also to fill the gaps and systematize the chain of care in accordance with the disease progression.

\section{Methods}

\section{Aims}

The aim of this study was to further develop and test the mapping system in a local context of nine Swedish municipalities. In addition, the aim was to assess availability and utilization of care activities as well as professional providers' educational level under the categories of Screening, the diagnostic procedures, and treatment, Outpatient care facilities, Institutional care and Palliative care.

\section{Context}

Health care in Sweden is performed in accordance with the Health and Medical Services Act [16] regulating the responsibility for health care across 21 counties and 290 municipalities. The county councils are responsible for health care, i.e. assessment and treatment, in hospitals and outpatient clinics. The municipalities are responsible for care and social services, i.e. home care and services, day care and nursing homes. Care for individuals aged 65 years and older and living at home, is granted after needs assessment, according to the Swedish Social Services Act [17].

\section{Design and sample}

This was a cross-sectional descriptive study of the care and services available to people with dementia and their informal caregivers throughout the course of the disease. The study population was nine municipalities (1-9) in two counties in southern Sweden. Data was collected during April to May 2015, by people knowledgeable about their municipality. Each municipality selected one or two contact persons representing the municipality. One municipality nominated three contact persons to have back-up in case of absences. These were professional providers such as registered nurses specialized in dementia, social workers and care coordinators with experience of dementia care. The researchers and contact persons had regular meetings, training and monitoring to discuss the description of the care activities and professionals, the meaning of availability and utilization and how to use the mapping system.

In all there were 220,641 inhabitants in the municipalities, $21 \%$ of whom were aged $0-17,58 \%$ who were aged $18-64$, and $21 \%$ who were 65 years or older. The number of inhabitants varied from 1944 to 88,108 , and three of the nine municipalities (municipalities 2, 5 and 6) represent rural areas. People with a foreign background accounted for $24.1 \%$ (mean) (range 21.4-26.8\%) of these municipal populations, compared with $22.2 \%$ for Sweden overall. In 2014, the nine municipalities together had 1087 persons with a dementia diagnosis [18].

\section{The mapping system}

The original mapping system horizontally explored five stages of the dementia disease - the diagnosis stage; early stage; intermediate stage; late stage; and end-of-life [19]. Vertically, 50 different types of care activities were listed and defined and they were based on how the disease progressed over time as reflected in type of care needs. Each aspect of the care activities included estimations of availability, utilization, and providers of care and service, at each stage of the dementia disease. This division in availability versus utilization was based on that availability can be common whilst in fact it is rarely used for various reasons. Response alternatives for estimations of availability were "For all", "For most", "For few" and "For no one"; and estimations of utilization were "By all", "By most", "By few", and "By no one". Professional care providers were classified regarding educational level in accordance with the ISCED [11] and were reported for each care activity [1].

The mapping system was adapted to the local context, in consensus with the researchers and contact persons in each municipality (Table 1). Each care activity was thoroughly.

discussed, as were the professional providers and their educational level according to the ISCED [11], until agreement was reached (Table 2). Where needed, specific professional

providers (a social worker or care manager) were contacted for accurate information. Furthermore, information was gathered from the internet regarding professionals, and their levels of education and care training descriptions. Care activities were removed, remained unchanged or were refined in the description. After minor adjustment in the descriptions of care activities, the mapping system was pilot tested in two municipalities, No changes were made after the pilot testing so the mapping system was adapted in the other seven participating municipalities. Data was collected according to the manual developed for this study, concerning availability and utilization of care activities for dementia care, and providers for each care activity during the last 6 months by the contact persons. 
Table 1 Care activities in the mapping system with newly added or; removed activities and refined description of activities

\begin{tabular}{|c|c|}
\hline Care activities in the original mapping system & Care activities in the developed mapping system \\
\hline Screening, the diagnostic procedures, and treatment & Screening, the diagnostic procedures and treatment \\
\hline Dementia screening programme/"case finding" & No changes \\
\hline Standard diagnostic procedure for dementia disease & No changes \\
\hline Pharmacological treatment specific for dementia disease & No changes \\
\hline Non-pharmacological treatment & No changes \\
\hline Pharmacological treatment specific for BPSD & No changes \\
\hline Non-pharmacological treatment specific for BPSD & No changes \\
\hline Memory clinic & No changes \\
\hline Outpatient care facilities & Outpatient care facilities \\
\hline Outpatient clinic specific for dementia diseases & Newly added activity - Specialized team in primary care for PwD \\
\hline Counselling & No changes \\
\hline Day care/Day activity/Day Care Centre/Day hospital & No changes \\
\hline $\begin{array}{l}\text { Day care/Day activity/Day Care Centre/Day hospital specialized } \\
\text { in dementia care }\end{array}$ & No changes \\
\hline Care at home & Care at home \\
\hline Will be presented elsewhere & One activity removed and will be presented elsewhere \\
\hline Institutional care & Institutional care \\
\hline Rehabilitation in institution & Newly added activity - Safety accommodation for people 70+ \\
\hline Residential home/Sheltered home/Assisted living & $\begin{array}{l}\text { Newly added subactivity }{ }^{a} \text { - Respite care, temporary and in case of } \\
\text { emergency }\end{array}$ \\
\hline Nursing home, for older people in general & $\begin{array}{l}\text { Newly added subactivity }{ }^{a} \text { - Respite care, specialized in dementia care, } \\
\text { temporary and in case of emergency }\end{array}$ \\
\hline \multicolumn{2}{|l|}{ Nursing home, specialized in dementia care } \\
\hline Nursing home, with dementia care units & Refined description - Community dwelling / Small housing for \\
\hline $\begin{array}{l}\text { Group dwelling/Small scaled living/Dementia patients' house } \\
\text { unit }\end{array}$ & people with dementia \\
\hline $\begin{array}{l}\text { Behavioural Intensive Care Unit/Psychogeriatric unit/ Geriatric } \\
\text { psychiatry inpatient unit }\end{array}$ & $\begin{array}{l}\text { Refined description - Psychogeriatric unit/Geriatric psychiatry } \\
\text { inpatient unit }\end{array}$ \\
\hline Respite care & Refined description - Respite care, temporary and planned \\
\hline Respite care, specialized in dementia care & $\begin{array}{l}\text { Refined description - Respite care, specialized in dementia care, } \\
\text { temporary and planned }\end{array}$ \\
\hline Palliative care & Palliative care \\
\hline Hospice/Institutional palliative care & No changes \\
\hline Hospice/Palliative care at home & No changes \\
\hline Advanced directive & No changes \\
\hline Informal caregiving and supportive actions & Informal caregiving and supportive actions \\
\hline Will be presented elsewhere & Will be presented elsewhere \\
\hline Civic organizations & Civic organizations \\
\hline Will be presented elsewhere & Two activities removed and will be presented elsewhere \\
\hline
\end{tabular}

BPSD Behavioural psychological symptoms in dementia, GPS Global positioning system, IADL Instrumental activities in daily life, PADL Personal activities in daily life, PwD Person with dementia

a existing activities subdivided into smaller parts

\section{Analysis}

Availability and utilization of care activities and the professionals' educational level were analysed descriptively with regard to variation for each of the four stages of the dementia disease and in each of the nine municipalities.
For all seven care categories included in the mapping system, response alternatives for availability and utilization of the 56 care activities were "For all" and "For most" and are given in bold in the Tables to distinguish from the response alternatives "For few" and "For no one". 
Table 2 Professional care providers' educational level in dementia care in Sweden, according to ISCED [11]

\begin{tabular}{|c|c|c|c|}
\hline ISCED LEVEL: & General health care training & Specialized health care training & Specialized training in dementia \\
\hline $\begin{array}{l}\text { 7: Master's or equivalent, } \\
\text { vocational }\end{array}$ & $\begin{array}{l}\text { Dentist (DE) investigates, treats } \\
\text { diseases and injuries in the teeth } \\
\text { and jaws. The treatment can range } \\
\text { from prevention and disease } \\
\text { treatment, to extensive and } \\
\text { technologically advanced clinical } \\
\text { interventions. } \\
\text { Dietician (DI) provides nutritional } \\
\text { counselling, prevention and } \\
\text { treatment } \\
\text { Medical doctor (MD), investigate, } \\
\text { treat and prevent diseases and other } \\
\text { health problems at hospitals and } \\
\text { health centres, in the pharmaceutical } \\
\text { industry or occupational health } \\
\text { services. } \\
\text { Psychologist (psychol) provides } \\
\text { counselling and help to people with } \\
\text { psychological problems. }\end{array}$ & $\begin{array}{l}\text { General practitioner (GP) physician } \\
\text { who treats patients within a district } \\
\text { for all types of diseases. } \\
\text { Medical doctor-internal medicine } \\
\text { (MD-int) specialized in internal } \\
\text { medicine. } \\
\text { Medical doctor-neurology (MD-neuro) } \\
\text { specialized in neurology. Training in } \\
\text { dementia is normally part of their } \\
\text { special training. } \\
\text { Medical doctor-psychiatry (MD-psych)/ } \\
\text { Old Age } \\
\text { Psychiatrist specialized in psychiatry. } \\
\text { Training in dementia is normally part } \\
\text { of their special training. } \\
\text { Psychologist-neuro (psychol-neuro) } \\
\text { psychologists specialized in cognitive } \\
\text { neuroscience, behaviour and brain } \\
\text { function. Administer }\end{array}$ & $\begin{array}{l}\text { Medical doctor-geriatrics (MD-ger) } \\
\text { geriatrician or psycho- geriatrician } \\
\text { specialized in geriatrics. } \\
\text { Occupational therapist (OT-dem) } \\
\text { Specialized in dementia (1 year } \\
\text { Master). } \\
\text { Physiotherapist (PT-dem) is } \\
\text { specialized in dementia } \\
\text { (1 year Master). } \\
\text { Registered nurse (RN dem) has the } \\
\text { overall responsibility for dementia } \\
\text { care in an area/municipality. Provides } \\
\text { counselling, supervision, and } \\
\text { assessments, and mediates contacts. } \\
\text { Education at advanced level: Care of } \\
\text { the elderly (1-year Master), District } \\
\text { nurse (1-year Master), Psychiatric care } \\
\text { (1-year Master), Dementia (1-year } \\
\text { Master). }\end{array}$ \\
\hline
\end{tabular}

Physiotherapist (PT) provides neuropsychological tests.

rehabilitation to identify and

improve, e.g., disabled movement and function.

Social worker (SW) provides staff

management for residential care or home help service.

Speech therapist (ST) treat communication problems due to

language, speech and voice disturbance including diagnostics and treatment of swallowing disorders.

6: Bachelor's or equivalent, vocational

5: Short-cycle tertiary education vocational
Case manager (CM) see "Specialized health care training".

Dietician (DI) provides nutritional counselling, prevention and treatment.

Occupational therapist (OT) provides rehabilitation to achieve optimum level of functional ability. This may include adaptation of the home and providing aids and equipment to assist with managing everyday activities.

Registered nurse (RN) provides care and service including help with PADLs, medical treatments, and managing the nursing care team. Physiotherapist (PT) provides rehabilitation to identify and improve, e.g., disabled movement and function.

Social worker (SW) provides staff management for residential care or home help service.

Speech therapist (ST) treat communication problems due to language, speech and voice disturbance including diagnostics and treatment of swallowing disorders. prevention by brushing and polishing the teeth as well as removing plaques. A dental hygienist may diagnose and treat caries, inflammation and dental loss.
Dental hygienist $(\mathrm{DH})$ helps special care needs
Case manager (CM) professional (RN or SW) function that may include finding and outreach, comprehensive assessment and care planning, coordination of service, service provision, monitoring, and evaluation, and, in addition, meeting

Community psychiatric registered nurse (RN-comm-psych) supports older people at home and in nursing/residential homes. Specialized in psychiatry Home help officer $(\mathrm{HO})$ carries out needs assessment prior to decision about home services and care
Occupational therapist (OT-dem) is specialized in dementia. Physiotherapist (PT-dem) is specialized in dementia. Registered nurse (RN dem) has an overall responsibility for dementia care in an area/municipality. Provides counselling, supervision, and assessments, and mediates contacts. Education at advanced level: Care of the elderly (1-year Master), Primary care (1-year Master), and Psychiatric care (1-year Master).
State examined nurses specialized in dementia care (SEN dem) not Bachelor's level. 
Table 2 Professional care providers' educational level in dementia care in Sweden, according to ISCED [11] (Continued)

\begin{tabular}{|c|c|c|c|}
\hline ISCED LEVEL: & General health care training & Specialized health care training & Specialized training in dementia \\
\hline $\begin{array}{l}\text { 4: Post-secondary non-tertiary, } \\
\text { vocational }\end{array}$ & $\begin{array}{l}\text { Licensed practical nurse (LPN)/ } \\
\text { Auxiliary nurse (Aux-N) provides care } \\
\text { and service including help with } \\
\text { IADLs and PADLs, and, in addition, } \\
\text { minor medical treatment. Health } \\
\text { care trained at secondary school } \\
\text { level. }\end{array}$ & & \\
\hline 3: Upper secondary, vocational & $\begin{array}{l}\text { Nurse aid/assistant nurse (Ass-N) } \\
\text { provides care and service including } \\
\text { help with IADLs and PADLs. Health } \\
\text { care trained for }<6 \text { months. } \\
\text { Support worker (Supp-work) home } \\
\text { carer, psychological supporter, or } \\
\text { home trainer paid at enhanced } \\
\text { nursing assistant/home carer rate. } \\
\text { Social care/nursing trained at } \\
\text { secondary level or trained on the } \\
\text { job. }\end{array}$ & & $\begin{array}{l}\text { Caregiver coordinator }(C C) \text { a } \\
\text { professional coordinating care for } \\
\text { people with dementia and informal } \\
\text { caregivers. }\end{array}$ \\
\hline$<3$ & $\begin{array}{l}\text { Occupational therapist assistant (OT-ass) } \\
\text { performs similar tasks as the OT. Not } \\
\text { trained, or trained on the job. } \\
\text { Social worker assistant (SW-ass) } \\
\text { performs similar tasks as the SW. } \\
\text { Not trained, or trained on the job. }\end{array}$ & & \\
\hline
\end{tabular}

IADL Instrumental activity of daily living, ISCED The International Standard Classification of Education, PADL Practical activity of daily living

Professionals involved in the care was recorded in a separate mapping system. The categories Screening, the diagnostic, procedures and treatment, Outpatient care facilities, Institutional care and Palliative care are described in this study. The three categories remaining, Care at home, Informal caregiving and supportive actions (including counselling and day care form Outpatient care facilities) and Civic organizations, will be reported elsewhere.

\section{Results}

\section{The developed mapping system}

When reviewing the care categories, all seven care categories were found to be valid and remained as in the original mapping system. A review was made of the stages of dementia as there were insignificant differences between estimations of availability and utilization in the diagnosis stage and the early stage. Consequently, the two stages were collapsed into one - the "early stage". For further development of the mapping system and to apply it to the local context, as well as to the national guidelines [20] and laws regulating health care and the social service system [16, 17], four care activities were added and three were removed (Table 1). Five care activities were refined in the description and subdivided to give ten care activities. The mapping system therefore covered 56 care activities and was found to be reliable after minor adaptation to the context.

New care activities were added under the categories Outpatient care facilities (namely "specialized team in primary care for persons with dementia"); Care at home ("contact person", in accordance with the Social Service Act and "respite care at home") (not shown in Table 1); and Institutional care ("safety accommodation for people aged 70+"). The care activity "nursing home, with dementia care units" was removed from the category Institutional care because nursing homes in Sweden either are for older people in general or are specialized in dementia care. Under the category Civic organizations, two care activities were removed; "paid voluntary organization" and "self-help organization/ self-support group".

As previously mentioned, minor changes were made to refine the definition of four care activities which were then subdivided to give ten care activities ("voluntary surveillance by telephone" and "technical equipment"; "voluntary aid"; two activities, one with and another without specialization in dementia care, of "respite care, temporary and planned"; two activities, one with and another without specialization in dementia care, of "respite care, temporary and in case of emergency"). Provision of vision and hearing aids was changed to "own activities" as people 65 years and older can get remittance from healthcare for vision and hearing aids. Under the care category Care at home, "foot care" was removed as it was considered to constitute self-management unless the person was diabetic. When comparing the nine municipalities for availability of 19 care activities throughout the course of the disease, the mean availability was 13 care activities (range 11-16). Four municipalities offered more than 13 care activities and two municipalities, one rural and one urban, offered 16 out of 19 care activities. 
Table 3 Availability and utilization of care activities in the category Screening, the diagnostic procedures, and treatment

\begin{tabular}{|c|c|c|c|c|c|c|c|c|c|}
\hline \multirow[t]{2}{*}{ Definition } & \multirow[t]{2}{*}{ Municipality* } & \multicolumn{2}{|c|}{ Early stage } & \multicolumn{2}{|c|}{ Intermediate stage } & \multicolumn{2}{|l|}{ Late stage } & \multicolumn{2}{|c|}{ End of life stage } \\
\hline & & $\begin{array}{l}\text { Available } \\
\text { for }\end{array}$ & $\begin{array}{l}\text { Utilized } \\
\text { by }\end{array}$ & $\begin{array}{l}\text { Available } \\
\text { for }\end{array}$ & $\begin{array}{l}\text { Utilized } \\
\text { by }\end{array}$ & $\begin{array}{l}\text { Available } \\
\text { for }\end{array}$ & $\begin{array}{l}\text { Utilized } \\
\text { by }\end{array}$ & $\begin{array}{l}\text { Available } \\
\text { for }\end{array}$ & $\begin{array}{l}\text { Utilized } \\
\text { by }\end{array}$ \\
\hline \multirow{9}{*}{$\begin{array}{l}\text { Dementia screening programme/"case } \\
\text { finding": Carried out in primary care } \\
\text { with the aim of detecting dementia at } \\
\text { early stages. Different assessment tools } \\
\text { might be used. }\end{array}$} & 1 & No one & No one & No one & No one & No one & No one & No one & No one \\
\hline & 2 & All & All & All & Few & All & No one & All & No one \\
\hline & 3 & No one & No one & No one & No one & No one & No one & No one & No one \\
\hline & 4 & All & Few & All & Few & All & Few & All & No one \\
\hline & 5 & No one & No one & No one & No one & No one & No one & No one & No one \\
\hline & 6 & No one & No one & No one & No one & No one & No one & No one & No one \\
\hline & 7 & All & Few & All & Few & All & Few & All & No one \\
\hline & 8 & All & Most & All & Most & All & Most & All & Most \\
\hline & 9 & All & Most & All & Most & All & Most & All & Most \\
\hline \multirow{9}{*}{$\begin{array}{l}\text { Standard diagnostic procedure for } \\
\text { dementia disease: National standard } \\
\text { diagnostic procedure applied in } \\
\text { accordance. }\end{array}$} & 1 & All & Most & All & Most & All & Few & All & No one \\
\hline & 2 & All & All & All & All & All & Few & - & - \\
\hline & 3 & All & Most & All & Most & All & Few & All & No one \\
\hline & 4 & No one & No one & No one & No one & No one & No one & No one & No one \\
\hline & 5 & All & Few & All & Most & All & Most & All & No one \\
\hline & 6 & All & Most & All & Most & All & Few & All & No one \\
\hline & 7 & All & Most & All & Most & All & Few & All & No one \\
\hline & 8 & All & Most & All & Most & All & Most & All & Few \\
\hline & 9 & All & Most & All & Most & All & Most & No one & No one \\
\hline \multirow{9}{*}{$\begin{array}{l}\text { Pharmacological treatment specific for } \\
\text { dementia disease: Medication of } \\
\text { cognitive symptoms, combined with } \\
\text { a likely slowing of disease progression, } \\
\text { for instance Cholinesterase Inhibitors } \\
\text { for improvement of cognition } \\
\text { (memory, language). ATC code } \\
\text { N06D [30]. Only validated treatment. }\end{array}$} & 1 & All & Most & All & Most & All & Few & All & No one \\
\hline & 2 & All & All & All & Few & All & No one & No one & No one \\
\hline & 3 & All & Most & All & Most & All & Few & All & No one \\
\hline & 4 & All & Most & All & Most & All & Most & All & No one \\
\hline & 5 & All & Few & All & Most & All & Most & All & Few \\
\hline & 6 & All & Few & All & Most & All & Most & All & Few \\
\hline & 7 & All & Most & All & Most & All & Few & All & No one \\
\hline & 8 & All & Most & All & Most & All & Few & All & Few \\
\hline & 9 & All & Few & All & Most & All & Most & All & Few \\
\hline \multirow{9}{*}{$\begin{array}{l}\text { Non-pharmacological treatment: } \\
\text { Treatment - not pharmacological, } \\
\text { for instance orientation to reality, } \\
\text { reminiscence therapy, tactile massage, } \\
\text { cognitive stimulation etc. }\end{array}$} & 1 & Few & Few & Few & Few & Few & Few & Few & Few \\
\hline & 2 & Most & Few & All & Most & All & Most & All & Few \\
\hline & 3 & Few & Few & Few & Few & Few & Few & Few & Few \\
\hline & 4 & All & Few & All & Most & All & Few & All & No one \\
\hline & 5 & All & Few & All & Most & All & Most & All & Few \\
\hline & 6 & All & Few & All & Few & All & Few & All & Few \\
\hline & 7 & All & Few & All & Most & Most & Few & Few & Few \\
\hline & 8 & All & Few & All & Few & All & Most & Most & Most \\
\hline & 9 & No one & No one & No one & No one & No one & No one & No one & No one \\
\hline \multirow{6}{*}{$\begin{array}{l}\text { Pharmacological treatment specific for } \\
\text { Behavioural Psychological Symptoms of } \\
\text { Dementia (BPSD): Pharmacological } \\
\text { treatment of non-cognitive symptoms } \\
\text { and behaviours, for instance psychotropic } \\
\text { drugs for aggressive behaviour [31]. ATC } \\
\text { code N05 [30]. }\end{array}$} & 1 & All & Few & All & Few & All & Few & All & Few \\
\hline & 2 & All & Few & All & Few & All & Most & All & Most \\
\hline & 3 & All & Few & All & Most & All & Most & All & Few \\
\hline & 4 & All & Most & All & Most & All & Most & All & Most \\
\hline & 5 & All & Few & All & Few & All & Few & All & Few \\
\hline & 6 & All & Most & All & Most & All & Most & All & Most \\
\hline
\end{tabular}


Table 3 Availability and utilization of care activities in the category Screening, the diagnostic procedures, and treatment (Continued)

\begin{tabular}{|c|c|c|c|c|c|c|c|c|c|}
\hline \multirow[t]{2}{*}{ Definition } & \multirow[t]{2}{*}{ Municipality* } & \multicolumn{2}{|l|}{ Early stage } & \multicolumn{2}{|c|}{ Intermediate stage } & \multicolumn{2}{|l|}{ Late stage } & \multicolumn{2}{|c|}{ End of life stage } \\
\hline & & $\begin{array}{l}\text { Available } \\
\text { for }\end{array}$ & $\begin{array}{l}\text { Utilized } \\
\text { by }\end{array}$ & $\begin{array}{l}\text { Available } \\
\text { for }\end{array}$ & $\begin{array}{l}\text { Utilized } \\
\text { by }\end{array}$ & $\begin{array}{l}\text { Available } \\
\text { for }\end{array}$ & $\begin{array}{l}\text { Utilized } \\
\text { by }\end{array}$ & $\begin{array}{l}\text { Available } \\
\text { for }\end{array}$ & $\begin{array}{l}\text { Utilized } \\
\text { by }\end{array}$ \\
\hline & 7 & All & Few & All & Few & All & Few & All & Few \\
\hline & 8 & Most & Few & All & Most & All & Most & All & Most \\
\hline & 9 & Most & Few & Most & Few & Most & Few & Most & Few \\
\hline \multirow{9}{*}{$\begin{array}{l}\text { Non-pharmacological treatment specific } \\
\text { for BPSD: Treatment - not } \\
\text { pharmacological, for instance } \\
\text { environmental modification, massage, } \\
\text { presence of pets, selected music, } \\
\text { distraction etc. [23]. }\end{array}$} & 1 & Few & Few & Most & Most & Most & Most & Most & Most \\
\hline & 2 & All & Few & All & Most & All & Most & All & Few \\
\hline & 3 & Few & Few & Few & Few & Few & Few & Few & Few \\
\hline & 4 & All & Few & All & Most & All & Most & All & Few \\
\hline & 5 & Few & Few & Most & Most & Most & Most & Most & Most \\
\hline & 6 & Most & No one & Most & Few & Most & Few & Most & Few \\
\hline & 7 & Most & Few & Most & Few & Most & Few & Most & Few \\
\hline & 8 & No one & No one & No one & No one & Few & Few & Few & Few \\
\hline & 9 & Few & Few & Few & Few & Few & Few & Few & Few \\
\hline \multirow{9}{*}{$\begin{array}{l}\text { Memory clinic: Outpatient clinic for } \\
\text { examination and treatment of memory } \\
\text { impairments, not only suspected } \\
\text { dementia diseases. }\end{array}$} & 1 & All & Few & All & Few & All & Few & All & No one \\
\hline & 2 & All & Few & All & Few & All & Few & All & No one \\
\hline & 3 & Few & Few & Few & Few & Few & Few & No one & No one \\
\hline & 4 & No one & No one & No one & No one & No one & No one & No one & No one \\
\hline & 5 & Few & Few & Few & Few & Few & Few & No one & No one \\
\hline & 6 & Few & No one & Few & Few & Few & Few & Few & No one \\
\hline & 7 & All & Few & All & Few & All & Few & All & Few \\
\hline & 8 & All & No one & All & No one & All & No one & All & No one \\
\hline & 9 & No one & No one & Few & Few & Few & Few & No one & No one \\
\hline
\end{tabular}

*1-9= represents the municipalities in two county councils in Sweden. ATC anatomical therapeutic chemical classification

${ }^{*} 1-9=$ represents the municipalities in two counties in Sweden

Staff training and professionals' educational level were added to apply to the Swedish health care and social service system. Concerning general health care training this was training to become a dentist, dietician, speech therapist, dental hygienist and occupational therapist assistant. Under "specialized health care training", "psychologist specialized in neuroscience" was added, and regarding specialized training in dementia, occupational therapy and physiotherapy were added. The provider category of "care coordinator", a professional coordinating care for people with dementia and their informal caregivers was added (Table 2).

Availability and utilization of care activities were higher for Screening, the diagnostic procedures, and treatment (Table 3) than for Outpatient care facilities (Table 4), Institutional care (Table 5) and Palliative care (Table 6). There were differences between availability and utilization of care activities in the nine municipalities, suggesting that the mapping system was able to assess and intercept variation. The educational level of professionals working in Screening, the diagnostic procedures and treatment (Table 7) was generally higher, mostly involving a Bachelor's to a Master's degree in
Science compared with the educational level of professionals working in Outpatient care facilities (Table 8), Institutional care (Table 9) and Palliative care (Table 10).

\section{Screening, the diagnostic procedures, and treatment}

The care category Screening, the diagnostic procedures, and treatment, involved identification and treatment of dementia diseases and included the dementia screening programme, standard diagnostic procedure for dementia diseases and memory clinics as well as pharmacological and non-pharmacological treatment for dementia and assessment of behavioural psychological symptoms of dementia (BPSD) (Table 3). Standard diagnostic procedure and pharmacological treatment for specific dementia diseases was available for all and utilized by most people with a suspected dementia disease, predominantly in the early and intermediate stage. There was availability of pharmacological treatment also for BPSD but less utilization. Non-pharmacological treatments for specific dementia diseases such as orientation to reality, reminiscence therapy, tactile massage, and cognitive stimulation were available in almost all municipalities and most of these treatments were utilized in the intermediate stage. 
Table 4 Availability and utilization of care activities in the category Outpatient care facilities

\begin{tabular}{|c|c|c|c|c|c|c|c|c|c|}
\hline \multirow[t]{2}{*}{ Definition } & \multirow[t]{2}{*}{ Municipality ${ }^{a}$} & \multicolumn{2}{|c|}{ Early stage } & \multicolumn{2}{|c|}{ Intermediate stage } & \multicolumn{2}{|c|}{ Late stage } & \multicolumn{2}{|c|}{ End of life stage } \\
\hline & & $\begin{array}{l}\text { Available } \\
\text { for }\end{array}$ & $\begin{array}{l}\text { Utilized } \\
\text { by }\end{array}$ & $\begin{array}{l}\text { Available } \\
\text { for }\end{array}$ & $\begin{array}{l}\text { Utilized } \\
\text { by }\end{array}$ & $\begin{array}{l}\text { Available } \\
\text { for }\end{array}$ & $\begin{array}{l}\text { Utilized } \\
\text { by }\end{array}$ & $\begin{array}{l}\text { Available } \\
\text { for }\end{array}$ & $\begin{array}{l}\text { Utilized } \\
\text { by }\end{array}$ \\
\hline \multirow{9}{*}{$\begin{array}{l}\text { Outpatient clinic specific for dementia } \\
\text { diseases: Outpatient clinic in primary } \\
\text { health care or in hospital, including } \\
\text { care by physicians and nurses specialized } \\
\text { in dementia. }\end{array}$} & 1 & No one & No one & No one & No one & No one & No one & No one & No one \\
\hline & 2 & All & Few & All & Few & All & Few & All & Few \\
\hline & 3 & Few & Few & Few & Few & Few & Few & Few & Few \\
\hline & 4 & No one & No one & No one & No one & No one & No one & No one & No one \\
\hline & 5 & No one & No one & No one & No one & No one & No one & No one & No one \\
\hline & 6 & No one & No one & No one & No one & No one & No one & No one & No one \\
\hline & 7 & Most & Most & Most & Most & Most & Few & Most & No one \\
\hline & 8 & Few & Few & Few & Few & Few & Few & Few & Few \\
\hline & 9 & No one & No one & No one & No one & No one & No one & No one & No one \\
\hline \multirow{9}{*}{$\begin{array}{l}\text { Specialized team in primary care for } \\
\text { persons with dementia: A team } \\
\text { specifically for people with dementia } \\
\text { with different professionals; medical } \\
\text { doctors, registered nurses, occupational } \\
\text { therapists, physiotherapist and licensed } \\
\text { practical nurses. }\end{array}$} & 1 & Most & Most & Most & Most & Few & Few & No one & No one \\
\hline & 2 & All & Most & All & Few & All & Few & All & Few \\
\hline & 3 & Few & Few & Few & Few & Few & Few & Few & Few \\
\hline & 4 & Few & Few & Most & Few & Most & Most & No one & No one \\
\hline & 5 & No one & No one & No one & No one & No one & No one & No one & No one \\
\hline & 6 & No one & No one & No one & No one & No one & No one & No one & No one \\
\hline & 7 & No one & No one & No one & No one & No one & No one & No one & No one \\
\hline & 8 & All & Few & All & Most & All & Most & All & Few \\
\hline & 9 & All & Most & All & Most & All & Few & All & No one \\
\hline
\end{tabular}

${ }^{a} 1-9=$ represents the municipalities in two counties in Sweden

Non-pharmacological treatment for BPSD, such as environmental modification, massage, presence of pets, selected music, and distraction was available in more than half of the municipalities and was mostly utilized in the intermediate stage. Dementia screening in primary care and memory clinics were less available throughout all stages of the dementia disease. Most people utilized screening (where this was available) in primary care in municipalities; by contrast, memory clinics were utilized by few or no one.

\section{Outpatient care facilities}

Outpatient care facilities included outpatient clinics specific for dementia and also specialized teams in primary care. Specialized teams in primary care may be necessary depending on the needs of the person with dementia and were more common than outpatient clinics for people with dementia. Where available, they were utilized by most in the early to intermediate stage (Table 4).

\section{Institutional care}

The care category Institutional care encompassed institutional rehabilitation, institutions or residential homes, and temporary or planned as well as specialized or not specialized care. Institutional rehabilitation and residential homes were available for all, but municipalities differed in utilization. Nursing homes for older people in general were available in more than half of the municipalities with variation regarding utilization. All the care activities under this category were utilized by most, predominantly in the late and end of life stage (Table 5). Availability of nursing homes and community dwellings with dementia care units as well as psychogeriatric units was rare in the municipalities and where they existed, they were utilized by most or all.

\section{Palliative care}

The care category Palliative care encompassed care at home, institutional care and advanced directive services. Home and institutional care was available for all in most of the municipalities through all stages of the dementia disease, but was utilized by few (Table 6). In one municipality, palliative care was available for no one. Advanced directive services were available for all in two municipalities through all stages of the dementia disease and for few or no one in the remaining seven municipalities. Where available, they were utilized by few except in the end of life stage.

Professionals providing care and their educational level Professionals providing the care in the care category Screening, the diagnostic procedures, and treatment most often held a Bachelor's degree to a Master's degree in 
Table 5 Availability and utilization of care activities in the category Institutional care

\begin{tabular}{|c|c|c|c|c|c|c|c|c|c|}
\hline \multirow[t]{2}{*}{ Definition } & \multirow[t]{2}{*}{ Municipality $^{\mathrm{a}}$} & \multicolumn{2}{|c|}{ Early stage } & \multicolumn{2}{|c|}{ Intermediate stage } & \multicolumn{2}{|c|}{ Late stage } & \multicolumn{2}{|c|}{ End of life stage } \\
\hline & & $\begin{array}{l}\text { Available } \\
\text { for }\end{array}$ & $\begin{array}{l}\text { Utilized } \\
\text { by }\end{array}$ & $\begin{array}{l}\text { Available } \\
\text { for }\end{array}$ & $\begin{array}{l}\text { Utilized } \\
\text { by }\end{array}$ & $\begin{array}{l}\text { Available } \\
\text { for }\end{array}$ & $\begin{array}{l}\text { Utilized } \\
\text { by }\end{array}$ & $\begin{array}{l}\text { Available } \\
\text { for }\end{array}$ & $\begin{array}{l}\text { Utilized } \\
\text { by }\end{array}$ \\
\hline \multirow{9}{*}{$\begin{array}{l}\text { Rehabilitation in institution: } \\
\text { Training in residential home/ } \\
\text { nursing home/group dwelling by } \\
\text { Occupational therapist, } \\
\text { Physiotherapist and/or registered } \\
\text { nurse and/or Licensed practical } \\
\text { nurse/Auxiliary nurse to improve } \\
\text { or maintain functional ability. }\end{array}$} & 1 & All & Few & All & Most & All & Most & All & Most \\
\hline & 2 & All & Few & All & Few & All & Few & All & Few \\
\hline & 3 & All & Few & All & Few & All & Most & All & Most \\
\hline & 4 & All & Few & All & Few & All & Few & All & Few \\
\hline & 5 & All & Few & All & Few & All & Few & All & Few \\
\hline & 6 & All & Few & All & Few & All & Few & All & Few \\
\hline & 7 & All & Most & All & Most & All & Most & All & Most \\
\hline & 8 & All & Most & All & Most & All & Most & All & Most \\
\hline & 9 & All & Most & All & Most & All & Most & All & Most \\
\hline \multirow{9}{*}{$\begin{array}{l}\text { Safety Accommodation: } \\
\text { Accommodation for people } 70+, \\
\text { not specifically for people with } \\
\text { dementia. The accommodation is } \\
\text { staffed specific hours every day to } \\
\text { offer joint meals and activities. }\end{array}$} & 1 & All & Few & All & Few & All & Few & All & No one \\
\hline & 2 & No one & No one & No one & No one & No one & No one & No one & No one \\
\hline & 3 & All & Few & All & Few & All & Few & All & Few \\
\hline & 4 & No one & No one & No one & No one & No one & No one & No one & No one \\
\hline & 5 & No one & No one & No one & No one & No one & No one & No one & No one \\
\hline & 6 & No one & No one & No one & No one & No one & No one & No one & No one \\
\hline & 7 & No one & No one & No one & No one & No one & No one & No one & No one \\
\hline & 8 & Most & Few & Most & Most & Most & Most & Few & Few \\
\hline & 9 & No one & No one & No one & No one & No one & No one & No one & No one \\
\hline \multirow{9}{*}{$\begin{array}{l}\text { Residential home/Sheltered } \\
\text { home/Assisted living. For older } \\
\text { people not specific for those with } \\
\text { dementia disease or mixed with } \\
\text { other older people: Housing with } \\
\text { care and service, i.e. home help } \\
\text { services or the like for people } \\
\text { who do not need daily attention } \\
\text { from registered nurses or } 24 \mathrm{~h} \\
\text { surveillance. }\end{array}$} & 1 & All & Few & All & Few & All & Few & All & Few \\
\hline & 2 & All & Few & All & Most & All & Most & All & Most \\
\hline & 3 & All & Few & All & Few & All & Most & All & Most \\
\hline & 4 & All & Few & All & Few & All & Most & All & All \\
\hline & 5 & All & No one & All & Few & All & Most & All & Most \\
\hline & 6 & All & No one & All & Few & All & Most & All & Most \\
\hline & 7 & All & Few & All & Few & All & Most & All & Most \\
\hline & 8 & All & Few & All & Few & All & Most & All & Most \\
\hline & 9 & All & Few & All & Most & All & All & All & Few \\
\hline \multirow{9}{*}{$\begin{array}{l}\text { Nursing home. Not specific for } \\
\text { those with dementia disease or } \\
\text { mixed with other older people: } \\
\text { Nursing care available } 24 / 7 \\
\text { provided by employed staff. May } \\
\text { include short-term rehab as well } \\
\text { as long-term care for people with } \\
\text { chronic impairments or disabilities } \\
\text { requiring daily attention of registered } \\
\text { nurses to help with personal care or } \\
\text { mobility. }\end{array}$} & 1 & All & Few & All & Most & All & Most & All & Most \\
\hline & 2 & All & No one & All & Few & All & Most & All & Most \\
\hline & 3 & All & Few & All & Few & All & Most & All & Most \\
\hline & 4 & No one & No one & Few & Few & All & Most & All & Most \\
\hline & 5 & No one & No one & No one & No one & No one & No one & No one & No one \\
\hline & 6 & No one & No one & No one & No one & No one & No one & No one & No one \\
\hline & 7 & All & No one & All & Few & All & Most & All & Most \\
\hline & 8 & No one & No one & No one & No one & No one & No one & No one & No one \\
\hline & 9 & No one & No one & All & Few & All & Few & No one & No one \\
\hline \multirow{6}{*}{$\begin{array}{l}\text { Nursing home with dementia } \\
\text { care units: Nursing homes } \\
\text { especially designed and adapted } \\
\text { environment to meet the needs } \\
\text { of people with dementia. Nursing } \\
\text { care available } 24 / 7 \text { provided by } \\
\text { employed staff. Units with } \\
\text { staff specialized in dementia. }\end{array}$} & 1 & All & Few & All & Most & All & Most & All & Most \\
\hline & 2 & No one & No one & No one & No one & No one & No one & No one & No one \\
\hline & 3 & No one & No one & No one & No one & No one & No one & No one & No one \\
\hline & 4 & No one & No one & No one & No one & All & Most & All & Most \\
\hline & 5 & No one & No one & No one & No one & No one & No one & No one & No one \\
\hline & 6 & No one & No one & No one & No one & No one & No one & No one & No one \\
\hline
\end{tabular}


Table 5 Availability and utilization of care activities in the category Institutional care (Continued)

\begin{tabular}{|c|c|c|c|c|c|c|c|c|c|}
\hline \multirow[t]{2}{*}{ Definition } & \multirow[t]{2}{*}{ Municipality $^{a}$} & \multicolumn{2}{|c|}{ Early stage } & \multicolumn{2}{|c|}{ Intermediate stage } & \multicolumn{2}{|c|}{ Late stage } & \multicolumn{2}{|c|}{ End of life stage } \\
\hline & & $\begin{array}{l}\text { Available } \\
\text { for }\end{array}$ & $\begin{array}{l}\text { Utilized } \\
\text { by }\end{array}$ & $\begin{array}{l}\text { Available } \\
\text { for }\end{array}$ & $\begin{array}{l}\text { Utilized } \\
\text { by }\end{array}$ & $\begin{array}{l}\text { Available } \\
\text { for }\end{array}$ & $\begin{array}{l}\text { Utilized } \\
\text { by }\end{array}$ & $\begin{array}{l}\text { Available } \\
\text { for }\end{array}$ & $\begin{array}{l}\text { Utilized } \\
\text { by }\end{array}$ \\
\hline & 7 & All & No one & All & Few & All & Most & All & Most \\
\hline & 8 & No one & No one & No one & No one & No one & No one & No one & No one \\
\hline & 9 & No one & No one & No one & No one & No one & No one & No one & No one \\
\hline \multirow{9}{*}{$\begin{array}{l}\text { Community Dwelling / Small } \\
\text { housing for people with } \\
\text { dementia: Housing especially } \\
\text { designed and adapted environment } \\
\text { to meet the needs of people with } \\
\text { dementia. Staff specifically trained in } \\
\text { dementia care. Only for people with } \\
\text { dementia ( } \leq 10 \text { people) }\end{array}$} & 1 & All & Few & All & Most & All & Most & All & All \\
\hline & 2 & All & No one & All & Few & All & Most & All & Most \\
\hline & 3 & No one & No one & No one & No one & No one & No one & No one & No one \\
\hline & 4 & No one & No one & No one & No one & No one & No one & No one & No one \\
\hline & 5 & No one & No one & Few & Few & Few & Few & Few & Few \\
\hline & 6 & All & No one & All & No one & All & Few & All & Few \\
\hline & 7 & No one & No one & No one & No one & No one & No one & No one & No one \\
\hline & 8 & No one & No one & No one & No one & No one & No one & No one & No one \\
\hline & 9 & No one & No one & No one & No one & No one & No one & No one & No one \\
\hline \multirow{9}{*}{$\begin{array}{l}\text { Psychogeriatric unit/Geriatric } \\
\text { psychiatry inpatient unit: Units } \\
\text { where patients are provided } \\
\text { inpatient care during a short- } \\
\text { intermediate period (weeks to } \\
\text { some months), with the aim of } \\
\text { controlling acute BPSD. Staff } \\
\text { specialized in dementia management. } \\
\text { Only people with dementia is } \\
\text { signed in. }\end{array}$} & 1 & No one & No one & No one & No one & No one & No one & No one & No one \\
\hline & 2 & No one & No one & Few & No one & Few & No one & No one & No one \\
\hline & 3 & No one & No one & No one & No one & No one & No one & No one & No one \\
\hline & 4 & - & - & - & - & - & - & - & - \\
\hline & 5 & No one & No one & Few & Few & Few & Few & No one & No one \\
\hline & 6 & No one & No one & No one & No one & No one & No one & No one & No one \\
\hline & 7 & No one & No one & No one & No one & No one & No one & No one & No one \\
\hline & 8 & Few & Few & Few & Few & Most & Most & Most & Most \\
\hline & 9 & Few & No one & Few & Few & Few & No one & No one & No one \\
\hline
\end{tabular}

${ }^{\mathrm{a}} 1-9=$ represents the municipalities in two counties in Sweden

Science (Table 7). Professionals holding a post-secondary qualification or a Bachelor's degree provided nonpharmacological treatment. Professionals in some municipalities were specialized in dementia care, most often in the standard diagnostic procedure for dementia diseases or in memory clinics. Outpatient care facilities in several municipalities engaged professionals holding a Bachelor's or a Master's degree (Table 8). In one municipality, professionals held a post-secondary education; professionals specialized in dementia care were rare. Professionals involved in Institutional care in residential homes, nursing homes and community dwellings held a post-secondary educational level, a Bachelor's, or Master's degree (Table 9). Professionals specialized in dementia care most often worked in residential homes. Palliative care was provided by professionals educated to a post-secondary educational level or holding a Bachelor's or Master's degree, some of whom were specialized in dementia care (Table 10).

\section{Discussion}

The previously developed mapping system for dementia care was found to be reliable after making minor adaptation to the context at the local level, i.e. the nine municipalities studied. The categories developed were found to be robust and no changes were needed; however slight adaptations to definitions were needed. Adaptation of activities in the different municipalities was also needed. The differences between estimations of availability and utilization in the diagnosis stage and early stage were insignificant the two stages were collapsed into one stage, the "early stage". Care activities were added and removed to fit the local context although not many alterations were made. Furthermore, minor adjustments were made to the definitions of care activities through the course of the dementia disease.

The results revealed a range of different care activities, more than contained in the original mapping system. These results suggest that the mapping system is a valid tool for exploring and comparing care and service systems for persons with dementia and their caregivers at a local level. However adaptations may be needed in terms of care activities offered and their definition. Further, the results revealed differences between the nine municipalities and allowed comparison between municipalities that are responsible for the care of people with 
Table 6 Availability and utilization of care activities in the category Palliative care

\begin{tabular}{|c|c|c|c|c|c|c|c|c|c|}
\hline \multirow[t]{2}{*}{ Definition } & \multirow[t]{2}{*}{ Municipality $^{\mathrm{a}}$} & \multicolumn{2}{|c|}{ Early stage } & \multicolumn{2}{|c|}{ Intermediate stage } & \multicolumn{2}{|c|}{ Late stage } & \multicolumn{2}{|c|}{ End of life stage } \\
\hline & & $\begin{array}{l}\text { Available } \\
\text { for }\end{array}$ & $\begin{array}{l}\text { Utilized } \\
\text { by }\end{array}$ & $\begin{array}{l}\text { Available } \\
\text { for }\end{array}$ & $\begin{array}{l}\text { Utilized } \\
\text { by }\end{array}$ & $\begin{array}{l}\text { Available } \\
\text { for }\end{array}$ & $\begin{array}{l}\text { Utilized } \\
\text { by }\end{array}$ & $\begin{array}{l}\text { Available } \\
\text { for }\end{array}$ & $\begin{array}{l}\text { Utilized } \\
\text { by }\end{array}$ \\
\hline \multirow{9}{*}{$\begin{array}{l}\text { Hospice/Palliative care at home: } \\
\text { Hospice is a type of care and a } \\
\text { philosophy of care that focuses on } \\
\text { the palliation of a terminally ill } \\
\text { patient's symptoms. The focus } \\
\text { should be on physical, emotional, } \\
\text { spiritual or social needs [23]. The } \\
\text { care is provided at home. }\end{array}$} & 1 & All & Few & All & Few & All & Few & All & Few \\
\hline & 2 & All & Most & All & Most & All & Most & All & Few \\
\hline & 3 & All & Few & All & Few & All & Few & All & Few \\
\hline & 4 & All & All & All & All & All & All & All & All \\
\hline & 5 & All & Few & All & Few & All & Few & All & Few \\
\hline & 6 & All & No one & All & Few & All & Few & All & Few \\
\hline & 7 & All & Few & All & Few & All & Few & All & Few \\
\hline & 8 & No one & No one & No one & No one & No one & No one & No one & No one \\
\hline & 9 & All & Few & All & Few & All & Few & All & Few \\
\hline \multirow{9}{*}{$\begin{array}{l}\text { Hospice/Institutional palliative care: } \\
\text { Hospice is a type of care and a } \\
\text { philosophy of care that focuses on } \\
\text { the palliation of a terminally ill } \\
\text { patient's symptoms. The focus } \\
\text { should be on physical, emotional, } \\
\text { spiritual or social needs [23]. The } \\
\text { palliative care is provided in } \\
\text { hospitals or nursing homes. }\end{array}$} & 1 & All & Few & All & Few & All & Few & All & Few \\
\hline & 2 & All & Most & All & Most & All & Most & All & All \\
\hline & 3 & All & Few & All & Few & All & Most & All & All \\
\hline & 4 & All & All & All & All & All & All & All & All \\
\hline & 5 & All & Few & All & Few & All & Few & - & - \\
\hline & 6 & All & No one & All & Few & All & Few & All & No one \\
\hline & 7 & All & No one & All & Few & All & Most & All & All \\
\hline & 8 & No one & No one & No one & No one & No one & No one & No one & No one \\
\hline & 9 & All & Few & All & Few & All & Few & All & Few \\
\hline \multirow{9}{*}{$\begin{array}{l}\text { Advanced directive: Living will and } \\
\text { power of attorney. }\end{array}$} & 1 & All & Few & All & Few & All & Few & All & Few \\
\hline & 2 & All & Few & All & Few & All & Few & All & Few \\
\hline & 3 & No one & No one & No one & No one & No one & No one & No one & No one \\
\hline & 4 & No one & No one & No one & No one & No one & No one & No one & No one \\
\hline & 5 & Few & Few & Few & Few & Few & Few & Few & Few \\
\hline & 6 & No one & No one & No one & No one & No one & No one & No one & No one \\
\hline & 7 & No one & No one & No one & No one & No one & No one & No one & No one \\
\hline & 8 & No one & No one & No one & No one & No one & No one & No one & No one \\
\hline & 9 & No one & No one & No one & No one & No one & No one & No one & No one \\
\hline
\end{tabular}

${ }^{\mathrm{a}} 1-9=$ represents the municipalities in two counties in Sweden

dementia, also making the options for care and support visible. It is well known that people with dementia and their caregivers have individual needs throughout the stages of dementia. Some have reported perceiving health care professionals as reactive rather than proactively informing the patient and their caregiver(s) about the disease progression and the support available to meet their needs [5]. By systematically exploring the available care activities, professionals and policy makers could be proactive in their communication with care recipients and fill gaps where needed. In order to further bring light on what is needed throughout the course of dementia it would be worthwhile to interview the informal caregivers and the person with dementia to find out what they know about options throughout the disease progression.
Persons with dementia in the nine municipalities do not all seem to have equal access to care and services despite the existing national or local guidelines for dementia care. For instance, in this study, standard diagnostic procedure for dementia diseases was available in all municipalities except one. In addition, there were differences between municipalities regarding dementia screening carried out in primary care and memory clinics. This might relate to availability of competence in the primary health care centres but also to adherence to guidelines which shows a diversity between the physicians' length of clinical experience and among patients [21]. Pharmacological treatment for dementia diseases was available for all, which is consistent with the results from Swedish national data $[1,2]$ and utilized by most. Pharmacological treatment for BPSD was available for all, 
Table 7 Professional care providers level of education in the category Screening, the diagnostic procedures, treatment of dementia

$\begin{array}{lllll}\text { ISCED level 7: Master's } & \text { ISCED level 6: } & \text { ISCED level 5: Short- } & \text { ISCED level 4: } & \text { ISCED level 3: } \\ \text { or equivalent, vocational } & \text { Bachelor's or } & \text { cycle tertiary education, } & \text { Post-secondary } & \text { Upper secondary, } \\ & \begin{array}{l}\text { equivalent, } \\ \text { vocational }\end{array} & \text { vocational } & \text { non-tertiary, } & \text { vocational } \\ & & \text { vocational } & \end{array}$

Dementia screening programme/"case

finding": Carried out in primary care with the aim of detecting dementia at early stages. Different assessment tools might be used.

Standard diagnostic procedure for dementia disease: National standard diagnostic procedure applied in accordance.

GP

GP

$4 \mathrm{GP}$

5 GP, MD psych,

6

7 GP, MD ger RN, RN dem, RN

distr, OT

8 GP, OT

$9 \mathrm{GP}$

1 GP, MD ger, RN dem, RN distr, Psychologist OT, SW

2 GP RN distr

3 GP RN, RN dem, RN

comm

4

5 GP, MD psych, RN dem, RN distr

$6 \mathrm{GP} \quad \mathrm{RN}$

$7 \mathrm{GP} \quad \mathrm{RN}, \mathrm{RN}$ distr, OT

$8 \mathrm{GP}$

$9 \mathrm{GP}$ OT

1 GP, MD ger

$2 \mathrm{GP} \quad \mathrm{RN}$

3 GP, MD psych, MD neuro

$4 \mathrm{GP}$

$\mathrm{RN}$

5 GP, MD psych,

$6 \mathrm{GP}$

$7 \mathrm{GP}$

$8 \mathrm{GP}$

$9 \mathrm{GP}$

Non-pharmacological treatment:

Treatment - not pharmacological,

for instance orientation to reality,

reminiscence therapy, tactile massage, cognitive stimulation etc.
1

2

5

6

7

8

9
LPN, LPN dem

OT

LPN, LPN

activity

LPN

SW-Ass

RN, RN dem, SW,

OT, PT

LPN

RN, RN dem, SW

LPN

RN, RN dem, RN distr, SW
LPN

LPN

LPN 
Table 7 Professional care providers level of education in the category Screening, the diagnostic procedures, treatment of dementia (Continued)

\begin{tabular}{|c|c|c|c|c|c|c|}
\hline & & $\begin{array}{l}\text { ISCED level 7: Master's } \\
\text { or equivalent, vocational }\end{array}$ & $\begin{array}{l}\text { ISCED level 6: } \\
\text { Bachelor's or } \\
\text { equivalent, } \\
\text { vocational }\end{array}$ & $\begin{array}{l}\text { ISCED level } 5 \text { : Short- } \\
\text { cycle tertiary education, } \\
\text { vocational }\end{array}$ & $\begin{array}{l}\text { ISCED level 4: } \\
\text { Post-secondary } \\
\text { non-tertiary, } \\
\text { vocational }\end{array}$ & $\begin{array}{l}\text { ISCED level 3: } \\
\text { Upper secondary, } \\
\text { vocational }\end{array}$ \\
\hline \multirow{9}{*}{$\begin{array}{l}\text { Pharmacological treatment specific for } \\
\text { Behavioural Psychological Symptoms of } \\
\text { Dementia (BPSD): Pharmacological } \\
\text { treatment of non-cognitive symptoms } \\
\text { and behaviours, psychotropic drugs for } \\
\text { aggressive behaviour [31]. } \\
\text { ATC code N05 [30]. }\end{array}$} & 1 & GP, MD ger. & & & & \\
\hline & 2 & & $\begin{array}{l}\text { RN, RN-distr, } \\
\text { RN-psych. }\end{array}$ & & & \\
\hline & 3 & GP, MD psych. & & & & \\
\hline & 4 & GP, MD ger. & RN-dem, SW & & & \\
\hline & 5 & GP, MD psych, & & & & \\
\hline & 6 & GP & & & & \\
\hline & 7 & GP & & & & \\
\hline & 8 & GP & & & & \\
\hline & 9 & GP & & & & \\
\hline \multirow{9}{*}{$\begin{array}{l}\text { Non-pharmacological treatment } \\
\text { specific for BPSD: Treatment - not } \\
\text { pharmacological, for instance } \\
\text { environmental modification, massage, } \\
\text { presence of pets, selected music, } \\
\text { distraction etc. [23]. }\end{array}$} & 1 & & $\begin{array}{l}\text { RN, RN-dem, dist, } \\
\text { elderly }\end{array}$ & & $\begin{array}{l}\text { LPN, LPN } \\
\text { activity. }\end{array}$ & \\
\hline & 2 & & & & $\begin{array}{l}\text { LPN, LPN } \\
\text { activity. }\end{array}$ & Ass-N \\
\hline & 3 & & OT & & $\begin{array}{l}\text { LPN, LPN } \\
\text { activity. }\end{array}$ & Ass-N \\
\hline & 4 & GP, MD ger. & $\begin{array}{l}\text { RN-dem, SW, OT, } \\
\text { FT }\end{array}$ & & & \\
\hline & 5 & & $\begin{array}{l}\text { RN, RN-dem, } \\
\text { RN-psych. }\end{array}$ & & & \\
\hline & 6 & & $\begin{array}{l}\text { RN, RN-dem, } \\
\text {-dist, SW, OT }\end{array}$ & & LPN & \\
\hline & 7 & & & & LPN & \\
\hline & 8 & & & & LPN & \\
\hline & 9 & & & & LPN & Ass-N \\
\hline \multirow{9}{*}{$\begin{array}{l}\text { Memory clinic: Outpatient clinic for } \\
\text { examination and treatment of } \\
\text { memory impairments, not only } \\
\text { suspected dementia diseases. }\end{array}$} & 1 & MD ger, Psychologist & RN dem, OT, sW & & & \\
\hline & 2 & & & & & \\
\hline & 3 & MD psych, & RN, RN-psych & & & \\
\hline & 4 & & & & & \\
\hline & 5 & MD psych, & RN-psych & & & \\
\hline & 6 & GP, MD ger, MD psych, & RN, RN-psych & & LPN & \\
\hline & 7 & MD psych, Psychologist & RN-psych, OT & & & \\
\hline & 8 & GP & & & & \\
\hline & 9 & MD ger. & & & & \\
\hline
\end{tabular}

but on the whole it was utilized by few which is in accordance with national directives [22]. Non-pharmacological treatment of BPSD, such as environmental modification, distraction, massage, presence of pets and listening to selected music [23], which should be easy to apply for professionals and which has few or no side effects, was available in six municipalities, where it was utilized by most in the intermediate to late stage. This was inconsistent with the RTPC study [1] where non-pharmacological treatment was available through all stages of the dementia disease. Outpatient care facilities in the present study were few and not often used, regardless of rural or urban location. Differences were found also between municipalities regarding institutional care specifically for people with dementia. This was available in fewer than half of the municipalities, regardless of rural or urban location. By contrast, in the end stage of life, palliative care was available in close to all municipalities with mixed utilization and 
Table 8 Professional care providers level of education in the category Outpatient care facilities

\begin{tabular}{|c|c|c|c|c|c|c|}
\hline & & $\begin{array}{l}\text { ISCED level 7: } \\
\text { Master's or } \\
\text { equivalent, } \\
\text { vocational }\end{array}$ & $\begin{array}{l}\text { ISCED level 6: } \\
\text { Bachelor's or } \\
\text { equivalent, } \\
\text { vocational }\end{array}$ & $\begin{array}{l}\text { ISCED level 5: } \\
\text { Short-cycle tertiary } \\
\text { education, vocational }\end{array}$ & $\begin{array}{l}\text { ISCED level 4: } \\
\text { Post-secondary } \\
\text { non-tertiary, vocational }\end{array}$ & $\begin{array}{l}\text { ISCED level 3: } \\
\text { Upper secondary, } \\
\text { vocational }\end{array}$ \\
\hline \multirow{9}{*}{$\begin{array}{l}\text { Outpatient clinic specific for dementia } \\
\text { diseases: Outpatient clinic in primary } \\
\text { health care or in hospital, including } \\
\text { care by physicians and nurses } \\
\text { specialized in dementia. }\end{array}$} & 1 & & & & & \\
\hline & 2 & GP & RN-distr & & & \\
\hline & 3 & GP & RN-dem & & & \\
\hline & 4 & & & & & \\
\hline & 5 & & & & & \\
\hline & 6 & & & & & \\
\hline & 7 & GP & $\begin{array}{l}\text { RN, RN-dem, } \\
\text { RN-psych, OT }\end{array}$ & & & \\
\hline & 8 & & RN-distr, & & & \\
\hline & 9 & & & & & \\
\hline \multirow{9}{*}{$\begin{array}{l}\text { Specialized team in primary care A team } \\
\text { specifically for people with dementia } \\
\text { with different professionals; medical } \\
\text { doctors, registered nurses, occupational } \\
\text { therapists, physiotherapist and licensed } \\
\text { practical nurses. }\end{array}$} & 1 & GP, Psychologist & RN-distr, OT & & & \\
\hline & 2 & GP & RN-distr & & & \\
\hline & 3 & & RN, RN-dem & & & \\
\hline & 4 & & & & & \\
\hline & 5 & & & & & \\
\hline & 6 & GP & $\mathrm{RN}$ & & LPN & \\
\hline & 7 & & & & & \\
\hline & 8 & GP & RN, RN-dem, OT & & & \\
\hline & 9 & GP & OT & & & \\
\hline
\end{tabular}

ISCED International Standard Classification of Education

For abbreviations of professional titles and qualifications, see Table 2

with no differences between municipalities. The quality of these care and treatment activities cannot be revealed by this study; however, by making the differences visible the study may initiate a process of discussing and developing a system based on the needs of the patients and their informal caregivers.

In accordance with the RTPC study [1] the present study shows differences between availability and utilization of care activities. Several care activities were available for all or most people with dementia, but utilized by few or no one, with some variation between municipalities and care categories. For instance, in the early to intermediate disease stage when diagnosis and treatment is needed, utilization was more frequent in the category Screening, the diagnostic procedures, and treatment. The modest availability of Outpatient care facilities, on the other hand may be due to smaller municipalities using the outpatient care facilities in larger municipalities. When the dementia disease progresses towards late and end of life stage, and the person with dementia has extensive care needs, there is an increase in utilization of institutional care and institutional palliative care.

There may be several explanations for non-utilization of available care activities in this study. One likely explanation is that the informal caregiver(s) and the care recipient may not be aware of the care and service activities that are available. It may also be that the care activities are not convenient or judged too expensive and/or too far away [10]. The visibility of the care is probably the most important explanation and this may coincide with a gate-keeper attitude. It has been shown that the system has been experienced as fragmented, with different professional providers and organizations responsible for different care and service activities, resulting in uncertainties regarding what to ask for and whom to contact within the care system $[6,7]$. At present, a coherent chain of care exists for cancer care in Sweden, but not yet for dementia care [24]. By systematically assessing availability of services and utilization, we can learn valuable knowledge about the local health care and social service system, which can form the basis for developing needed care activities, eliminating any that are not needed and communicating with those in need of support. It will make the chain of care visible and enable development of the existing health care and social service system at a local level for policy makers and professionals. This is essential to avoid a gate-keeper situation and instead ensure transparency, accessibility, and equal and individualized health care and social services for dementia care. Timely diagnosis and timely access to care 
Table 9 Professional care providers level of education in the category Institutional care

\begin{tabular}{|c|c|c|c|c|c|c|}
\hline & & $\begin{array}{l}\text { ISCED level 7: } \\
\text { Master's or } \\
\text { equivalent, } \\
\text { vocational }\end{array}$ & $\begin{array}{l}\text { ISCED level 6: } \\
\text { Bachelor's or equivalent, } \\
\text { vocational }\end{array}$ & $\begin{array}{l}\text { ISCED level 5: } \\
\text { Short-cycle tertiary } \\
\text { education, vocational }\end{array}$ & $\begin{array}{l}\text { ISCED level 4: } \\
\text { Post-secondary } \\
\text { non-tertiary, } \\
\text { vocational }\end{array}$ & $\begin{array}{l}\text { ISCED level 3: } \\
\text { Upper } \\
\text { secondary, } \\
\text { vocational }\end{array}$ \\
\hline \multirow{9}{*}{$\begin{array}{l}\text { Rehabilitation in institution: Training in } \\
\text { residential home/nursing home/group } \\
\text { dwelling by Occupational therapist, } \\
\text { Physiotherapist and/or registered nurses } \\
\text { and/or Licensed practical nurse/Auxiliary } \\
\text { nurse to improve or maintain functional ability. }\end{array}$} & 1 & & OT & & LPN & Ass-N \\
\hline & 2 & & OT, FT & & LPN, LPN-dem & \\
\hline & 3 & & $\mathrm{OT}, \mathrm{FT}$ & & LPN, LPN-dem & \\
\hline & 4 & & OT, FT & & LPN & Ass- $\mathrm{N}$ \\
\hline & 5 & & OT, FT & & LPN & \\
\hline & 6 & & OT, FT & & LPN & \\
\hline & 7 & & OT, FT & & LPN & Ass-N \\
\hline & 8 & & OT & & & \\
\hline & 9 & & OT & & LPN & Ass-N \\
\hline \multirow{9}{*}{$\begin{array}{l}\text { Safety accommodation: Accommodation } \\
\text { for people } 70+\text {, not specifically for people } \\
\text { with dementia. The accommodation is } \\
\text { staffed specific hours every day to offer } \\
\text { joint meals and activities. }\end{array}$} & 1 & & & & LPN, LPN-dem & Ass-N \\
\hline & 2 & & & & & \\
\hline & 3 & & & & $\mathrm{CC}$ & \\
\hline & 4 & & & & $\mathrm{CC}$ & \\
\hline & 5 & & & & & \\
\hline & 6 & & & & & \\
\hline & 7 & & & & & \\
\hline & 8 & & & & & \\
\hline & 9 & & & & & \\
\hline \multirow{9}{*}{$\begin{array}{l}\text { Residential home/Sheltered home/Assisted } \\
\text { living. For older people not specific for those } \\
\text { with dementia disease or mixed with other } \\
\text { older people: Housing with care and service, } \\
\text { for people who do not need daily attention } \\
\text { from registered nurses or } 24 \mathrm{~h} \text { surveillance. }\end{array}$} & 1 & & RN, RN-dem, SW, & & LPN, LPN-dem & Ass-N \\
\hline & 2 & GP & RN distr, RN psych, SW & & $\begin{array}{l}\text { LPN, LPN act, } \\
\text { CC }\end{array}$ & Ass-N \\
\hline & 3 & & $\begin{array}{l}\text { RN + dem, distr, } \\
\text { elderly, SW }\end{array}$ & & $\begin{array}{l}\text { LPN, LPN-dem, } \\
\text { CC }\end{array}$ & \\
\hline & 4 & & $\mathrm{RN}, \mathrm{OT}, \mathrm{FT}$ & & LPN & \\
\hline & 5 & GP & RN-dem, RN distr, FT & & & \\
\hline & 6 & GP & RN, RN distr, SW & & LPN & \\
\hline & 7 & & RN, RN-dem, SW & & LPN & Ass-N \\
\hline & 8 & & SW & & & \\
\hline & 9 & & SW & & LPN & Ass-N \\
\hline \multirow{9}{*}{$\begin{array}{l}\text { Nursing home. Not specifically dementia } \\
\text { disease or mixed with other older people: } \\
\text { Nursing care } 24 / 7 \text {, employed staff. May } \\
\text { include short-term rehab, long-term care } \\
\text { for people with chronic impairment or } \\
\text { disabilities requiring daily attention of } \\
\text { registered nurses to help with personal } \\
\text { care or mobility. }\end{array}$} & 1 & & RN, RN-dem, SW, & & LPN, LPN-dem & \\
\hline & 2 & GP & $\begin{array}{l}\text { RN-distr, psych, } \\
\text { elderly, SW, OT, FT }\end{array}$ & & $\begin{array}{l}\text { LPN, LPN-act, } \\
\text { CC }\end{array}$ & Ass-N \\
\hline & 3 & & $\begin{array}{l}\text { RN, RN-dem, distr, } \\
\text { eld, SW }\end{array}$ & & CC & \\
\hline & 4 & & $\mathrm{RN}, \mathrm{SW}, \mathrm{OT}, \mathrm{FT}$ & & LPN, & \\
\hline & 5 & & & & & \\
\hline & 6 & & & & & \\
\hline & 7 & & RN, RN-distr, SW & & LPN & Ass-N \\
\hline & 8 & & SW & & & \\
\hline & 9 & & & & LPN & Ass-N \\
\hline \multirow{3}{*}{$\begin{array}{l}\text { Nursing home with dementia care units: } \\
\text { Nursing homes especially designed and } \\
\text { adapted environment to meet the needs } \\
\text { of people with dementia. Nursing care } \\
\text { available } 24 / 7 \text { provided by employed staff. }\end{array}$} & 1 & & RN-, RN-dem, elderly, SW & & LPN, LPN-dem, & \\
\hline & 2 & & & & & \\
\hline & 3 & & & & & \\
\hline
\end{tabular}


Table 9 Professional care providers level of education in the category Institutional care (Continued)

\begin{tabular}{|c|c|c|c|c|c|c|}
\hline & & $\begin{array}{l}\text { ISCED level 7: } \\
\text { Master's or } \\
\text { equivalent, } \\
\text { vocational }\end{array}$ & $\begin{array}{l}\text { ISCED level 6: } \\
\text { Bachelor's or equivalent, } \\
\text { vocational }\end{array}$ & $\begin{array}{l}\text { ISCED level 5: } \\
\text { Short-cycle tertiary } \\
\text { education, vocational }\end{array}$ & $\begin{array}{l}\text { ISCED level 4: } \\
\text { Post-secondary } \\
\text { non-tertiary, } \\
\text { vocational }\end{array}$ & $\begin{array}{l}\text { ISCED level 3: } \\
\text { Upper } \\
\text { secondary, } \\
\text { vocational }\end{array}$ \\
\hline \multirow[t]{5}{*}{ Units with staff specialized in dementia } & 5 & & & & & \\
\hline & 6 & & & & & \\
\hline & 7 & & RN, RN-distr, SW & & LPN & Ass-N \\
\hline & 8 & & SW & & & \\
\hline & 9 & & & & & \\
\hline \multirow{9}{*}{$\begin{array}{l}\text { Community Dwelling / Small housing for } \\
\text { people with dementia: Housing especially } \\
\text { designed and adapted environment to } \\
\text { meet the needs of people with dementia. } \\
\text { Staff specifically trained in dementia care. } \\
\text { Only for people with dementia ( } \leq 10 \text { people) }\end{array}$} & 1 & & RN-, RN-dem, SW & & LPN, LPN-dem & Ass-N \\
\hline & 2 & GP & RN, RN--distr, OT, FT & & LPN, LPN-act & Ass-N \\
\hline & 3 & & & & & \\
\hline & 4 & & & & & \\
\hline & 5 & GP & RN-, RN-dem, SW & & LPN & \\
\hline & 6 & & & & & \\
\hline & 7 & & & & & \\
\hline & 8 & & & & & \\
\hline & 9 & & & & & \\
\hline \multirow{9}{*}{$\begin{array}{l}\text { Psychogeriatric unit/Geriatric psychiatry } \\
\text { inpatient unit: Units where people with } \\
\text { dementia are provided inpatient care, } \\
\text { short-intermediate period of time } \\
\text { (weeks to some months) with the aim } \\
\text { of controlling acute BPSD. Staff specialized } \\
\text { in dementia management }\end{array}$} & 1 & & & & & \\
\hline & 2 & & & & & \\
\hline & 3 & & & & & \\
\hline & 4 & & & & & \\
\hline & 5 & MD-psych & & & & \\
\hline & 6 & & & & & \\
\hline & 7 & & & & & \\
\hline & 8 & GP & & & & \\
\hline & 9 & & & & & \\
\hline
\end{tabular}

can help people with dementia and their caregivers in their care planning and enable them to take control over their situation [2].

The health professionals' educational level varied between the different care activities and municipalities, which may have affected the ability to provide high-quality care. Professionals with the lowest level of education were those involved in the everyday care of the persons with dementia and their caregivers in home and institutional palliative care, which is in line with findings from the European study [14]. For instance, those providing non-pharmacological treatment, held an upper-secondary ISCED qualification [11] while professionals working in institutional and palliative care were educated to upper-secondary ISCED level or above. The consequences of low professional education in the intimate care activities can be debated; this could for instance be detrimental for the quality of care but also for the staff's work environment. Professionals involved in screening, diagnosis and outpatient care held a Master's or in some cases, a Bachelor's degree. This is similar to the results reported from the RTPC study [14]. With an ageing population, the demands on long-term services will increase. To meet these demands, highly skilled staff are needed. It has been suggested that, to increase the quality of care and residents' quality of life, the competences of baccalaureate-educated registered nurses are needed [25].

Specialized training in dementia existed in the care categories analysed in this study, predominantly involving professionals with a Bachelor's degree but also those with an upper-secondary ISCED level education, which is inconsistent with the RTPC data [14]. This may be due to the national guidelines for dementia care. Also there is awareness among the public that professionals specialized in dementia care are able to provide individualized care throughout the course of the dementia disease [15]. Dementia specific education existed at different levels, from upper-secondary ISCED to Master's degree level. Specialized training in dementia was rare in 
Table 10 Professional care providers level of education in the category Palliative care

\begin{tabular}{|c|c|c|c|c|c|c|}
\hline & & $\begin{array}{l}\text { ISCED level 7: Master's } \\
\text { or equivalent, vocational }\end{array}$ & $\begin{array}{l}\text { ISCED level 6: } \\
\text { Bachelor's or } \\
\text { equivalent, } \\
\text { vocational }\end{array}$ & $\begin{array}{l}\text { ISCED level 5: } \\
\text { Short-cycle } \\
\text { tertiary education, } \\
\text { vocational }\end{array}$ & $\begin{array}{l}\text { ISCED level 4: } \\
\text { Post-secondary } \\
\text { non-tertiary, } \\
\text { vocational }\end{array}$ & $\begin{array}{l}\text { ISCED level 3: } \\
\text { Upper secondary, } \\
\text { vocational }\end{array}$ \\
\hline \multirow{9}{*}{$\begin{array}{l}\text { Hospice/Palliative care at home: Hospice } \\
\text { is a type of care and a philosophy of care, } \\
\text { which focuses on the palliation of a } \\
\text { terminally ill patient's symptoms. The focus } \\
\text { should be on physical, emotional, spiritual } \\
\text { or social needs [32]. The care is provided } \\
\text { at home. }\end{array}$} & 1 & GP, MD-ger & $\mathrm{RN}, \mathrm{RN}$-distr & & LPN, LPN-dem & Ass-N \\
\hline & 2 & GP & RN-distr, OT & & LPN, OT-ass & Ass-N \\
\hline & 3 & & $\mathrm{RN}, \mathrm{RN}$-distr & & LPN & Ass-N \\
\hline & 4 & & RN & & & \\
\hline & 5 & & $\begin{array}{l}\text { RN-dem, RN-distr, } \\
\text { SW }\end{array}$ & & LPN & \\
\hline & 6 & GP & $\begin{array}{l}\text { RN, RN-distr, SW, } \\
\text { OT, FT }\end{array}$ & & LPN & \\
\hline & 7 & GP & $\mathrm{RN}, \mathrm{RN}$-distr & & LPN & \\
\hline & 8 & & & & & \\
\hline & 9 & & RN & & & \\
\hline \multirow{9}{*}{$\begin{array}{l}\text { Hospice/Institutional palliative care: Hospice } \\
\text { is a type of care and a philosophy of care, } \\
\text { which focuses on the palliation of a terminally } \\
\text { ill patient's symptoms. The focus should be } \\
\text { on physical, emotional, spiritual or social } \\
\text { needs [32]. The palliative care is provided in } \\
\text { hospitals or nursing homes }\end{array}$} & 1 & GP, MD-ger & $\mathrm{RN}-$, RN-dem & & LPN, LPN-dem & Ass-N \\
\hline & 2 & GP & RN, RN-distr, OT, FT & & LPN & Ass-N \\
\hline & 3 & & RN, RN-distr, & & LPN & Ass-N \\
\hline & 4 & & RN & & & \\
\hline & 5 & GP & $\begin{array}{l}\text { RN-dem, RN-distr, } \\
\text { SW }\end{array}$ & & LPN & \\
\hline & 6 & GP & $\begin{array}{l}\text { RN, RN-dem,/distr, } \\
\text { SW, OT, FT }\end{array}$ & & LPN & \\
\hline & 7 & GP & $\mathrm{RN}, \mathrm{RN}$-distr & & LPN & \\
\hline & 8 & & & & & \\
\hline & 9 & & RN & & & \\
\hline \multirow[t]{9}{*}{$\begin{array}{l}\text { Advanced directive: Living will and power } \\
\text { of attorney }\end{array}$} & 1 & GP, MD-psych & $\begin{array}{l}\text { RN-, RN-elderly/ } \\
\text { distr }\end{array}$ & & & \\
\hline & 2 & & $\mathrm{RN}-$, RN-distr & & & \\
\hline & 3 & & & & & \\
\hline & 4 & & & & & \\
\hline & 5 & & & & & \\
\hline & 6 & & & & & \\
\hline & 7 & & & & & \\
\hline & 8 & & & & & \\
\hline & 9 & & & & & \\
\hline
\end{tabular}

ISCED International Standard Classification of Education [11]

For abbreviations of professional titles and qualifications, see Table 2

this study, and existed in fewer than half of the municipalities. Notable was that professionals specialized in dementia care were involved in the care of elderly patients in general, indicating that, in these municipalities, it was considered important to be able to care for people with dementia at general facilities. It is essential that professionals providing health care and social services to persons with dementia and their informal caregivers have relevant education and knowledge so that they can provide dementia-specific, individualized care and services [26, 27]. Research is sparse and further research is needed regarding whether specialized training in dementia has an impact on the quality of care for people with dementia living at home and in nursing homes [25, 28].

This study has limitations. We are only starting to investigate the system of care and services for a severe disease like dementia. It may be that the response alternatives for availability and utilization were too vague. Also the data were collected during April and May 2015 and it is possible that data would be different if collected today. Attempts were made to define each care activity; however, the descriptions are still open to interpretation, e.g. by the professionals. To address this problem, those 
performing the data collection were given specific training and instructions. The quality of the care activities cannot be stated in this study although some indications depending on the educational level of those involved can be seen. Also, the reasons for differences between availability and utilization needs to be further explored and so also does how the options in the system are communicated to those who might need it. Furthermore, no data were collected on how responsibility for care and services was distributed in real life. For people with dementia and their caregivers, it is of utmost importance to know who is responsible for which care activities and who to turn to. The mapping system can, and needs to, be adapted to each heath care and social service system and to national guidelines where available. To strengthen the mapping system for interconnection, descriptions of care activities should be more specific to avoid interpretation by professionals. Non-uptake of services and additional needs and the link between these may have to be studied further by additional interviews or surveys to get an idea of the complexities of the chain of care.

The strength of this study was that each municipality was given the same instructions for data collection, ensuring reliability. A pilot test of the developed mapping system was performed after re-fining descriptions of care activities and providers. However, each contact person reported availability and utilization of municipality care and services, as well as providers' educational level, from a local perspective, which may have affected the validity of the results. Testing the mapping system at a local level, regarding availability and utilization of care activities and professionals educational level, and further, comparing local data between municipalities worked well, thus revealing differences that suggest that the mapping system is an instrument able to assess and intercept variation.

\section{Conclusions}

A previously developed mapping system for investigating resources in health care and social services for people with dementia and their informal caregivers was adapted and tested in nine municipalities in Sweden to enable its use at a local level. Minor context-related changes were made regarding care activities and professionals' educational level. The categories capturing the type of care activities available was found to be reliable. The system enables professionals and policy makers to reveal strengths and weaknesses in the health care and social services system when providing care and services on equal terms for people with dementia and their informal caregivers. Mapping the educational level of professionals providing the care and services may reveal, where in the chain of care, dementia-specific education for professionals needs to be developed. Further, the mapping system may enable professionals to be proactive and communicate available care and services to people with dementia and their caregivers throughout the course of the dementia disease. This is also invaluable in policymaking.

\section{Acknowledgements \\ We are grateful for Professor Ulla Melin Emilsson's contribution to development of the "Living with dementia" project from the underlying RTPC study and to Professor Staffan Karlsson for his contribution during the planning stage and data collection. \\ Funding \\ This work is part of the project "Living with dementia, care and social service systems", supported by a grant from the Kamprad Family Foundation (Contract number 2013121). In addition, the Department of Social Work at Linnaeus University, the Alzheimer's Society and the Greta and Johan Kocks Foundation funded this study. The funding body was not involved in the design of the study, the collection, analysis and interpretation of data, nor in writing the manuscript.}

\section{Availability of data and materials}

The datasets used and/or analysed during the current study are available from the corresponding author on reasonable request.

\section{Authors' contributions}

All authors contributed to the study design, interpretation, writing and revision of this publication. The first author, $\mathrm{CL}$, drafted the manuscript and analysed the data. CL, LG and ELV conducted the data collection and ELV organized the data. IRH planned the "Living with dementia" study and developed the mapping system. All authors have read and approved the final manuscript.

\section{Ethics approval and consent to participate}

This study complies with the ethical principles of the Helsinki declaration [29]. Ethical approval for the study was granted by the Regional Ethical Review Board in Lund, Sweden (2010/538; additional application 2014/ 765). The Head of Social Services in each municipality signed informed consent prior to data collection.

Consent for publication

Not applicable.

\section{Competing interests}

The authors declare that they have no competing interests.

\section{Publisher's Note}

Springer Nature remains neutral with regard to jurisdictional claims in published maps and institutional affiliations.

\section{Author details \\ ${ }^{1}$ Faculty of Medicine, Department of Health Sciences, Lund University, PO Box 157, 22100 Lund, Sweden. ²Department of Social Work, Linnaeus University, Universitetsplatsen 1, 35195 Växjö, Sweden. ${ }^{3}$ Faculty of Medicine, Department of Clinical Sciences, Clinical Memory Research Unit, Lund, Sweden.}

Received: 7 November 2017 Accepted: 1 October 2018 Published online: 16 October 2018

\footnotetext{
References

1. Hallberg IR, Leino-Kilpi H, Meyer G, Raamat K, Soto Martin M, Sutcliffe C, et al. Dementia care in eight European countries; developing a mapping system to explore systems. J Nurs Scholarsh. 2013;45:412-24. https://doi.org/ 10.1111/jnu.12046. Epub 2013 Sep 11.

2. Winblad B, Amouyel $P$, Andrieu S, Ballard C, Brayne C, Brodaty $H$, et al. Defeating Alzheimer's disease and other dementias: a priority for European
} 
science and society. Lancet Neurol. 2016;15:455-532. https://doi.org/10. 1016/S1474-4422(16)00062-4.

3. lecovich E. Aging in place: from theory to practice. Anthropol Notebooks. 2014;20:21-34

4. Kannaley K, Mehta S, Yelton B, Friedman DB. Thematic analysis of blog narratives written by people with Alzheimer's disease and other dementias and care partners. Dementia (London). 2018;1:1471301218768162. https:// doi.org/10.1177/1471301218768162. [Epub ahead of print].

5. Lethin C, Hallberg IR, Karlsson S, Janlöv A-C. Family caregivers experiences of formal care when caring for persons with dementia through the process of the disease. Scand J Caring Sci. 2016;30(3):526-34. https://doi.org/10. 1111/scs.12275. Epub 2015 Sep 8.

6. Wiles J. Informal caregivers' experiences of formal support in a changing context. Health Soc Care Community. 2003;11:189-207.

7. McCormack B, Mitchell EA, Cook G, Reed J, Childs S. Older persons' experiences of whole systems: the impact of health and social care organizational structures. J Nurs Manag. 2008;16:105-14.

8. McCabe M, You E, Tatangelo G. Hearing their voice: a systematic review of dementia family Caregivers' needs. Gerontologist. 2016;56:e70-88. https:// doi.org/10.1093/geront/gnw078. Epub 2016 Apr 21.

9. Prince $M$, Prina $M$, Guerchet $M$. World Alzheimer report. journey of caring. an analysis of long-term care for dementia. London: Alzheimer's disease International; 2013. http://www.alz.co.uk/research/ WorldAlzheimerReport2013.pdf. Accessed 25 Jul 2018

10. Levesque JF, Harris MF, Rusell G. Patient-centred access to health care: conceptualising access at the interface of health systems and populations. Int J Equity Health. 2013;11;12:18. https://doi.org/10.1186/1475-9276-12-18.

11. International Standard Classification of Education (ISCED). United Nations educational, scientific and cultural organization (UNESCO). 2011. http://uis. unesco.org/sites/default/files/documents/international-standard-classi fication-of-education-isced-2011-en.pdf. Accessed 25 Jul 2018.

12. Jones J, Hunter D. Consensus methods for medical and health services research. BMJ. 1995;311:376-80.

13. Bökberg C, Ahlström G, Leino-Kilpi H, Soto-Martin ME, Cabrera E, Verbeek H, et al. Care and Service at Home for persons with dementia in Europe. J Nurs Scholarsh. 2015;47:407-16. https://doi.org/10.1111/jnu.12158. Epub 2015 Aug 7.

14. Hallberg IR, Cabrera E, Jolley D, Raamat K, Renom-Guiteras A, Verbeek H, et al. Professional care providers in dementia care in eight European countries; their training and involvement in early dementia stage and in home care. Dementia (London). 2016;15:931-57. https://doi.org/10.1177/ 1471301214548520. Epub 2014 Sep 2.

15. Lethin C, Leino-Kilpi H, Roe B, Soto Martin M, Saks K, Stephan A, et al. Formal support for informal caregivers to older persons with dementia through the course of the disease: an exploratory, cross-sectional study. BMC Geriatr. 2016;29;16:32. https://doi.org/10.1186/s12877-016-0210-9.

16. SFS 1982:763. Health and Medical Services Act. The Swedish Government. https://www.riksdagen.se/sv/dokument-lagar/dokument/svenskforfattningssamling/halso--och-sjukvardslag-1982763_sfs-1982-763. Accessed 25 Jul 2018

17. SFS 2001:453. Social Service Act. The Swedish Government. http://www. riksdagen.se/sv/dokument-lagar/dokument/svensk-forfattningssamling/ socialtjanstlag-2001453_sfs-2001-453. Accessed 25 Jul 2018.

18. Statistics Sweden. Folkmängden efter region, civilstånd, ålder och kön. År 1968 - 2015. 2015. http://www.statistikdatabasen.scb.se/pxweb/sv/ssd/ START_BE_BE0101_BE0101A/BefolkningNy/?rxid=ee5011 b9-bba5-4f2c9010-d29c35efc659. Accessed 8 Oct 2018.

19. Moise $P$, Schwarzinger M, Um MY. Dementia care in 9 OECD countries: a comparative analysis. OECD health working papers 2004. 2004;13(5):1-109. http://www.oecd.org/els/health-systems/33661491.pdf. Accessed 25 Jul 2018.

20. The National Board of Health and Welfare. Nationella Riktlinjer för Vård och Omsorg vid Demenssjukdom - Stöd för Styrning och Ledning. (National Guidelines for Care and Service in Dementia - Support for Governance and Management). 2017, Åtta.45 Tryckeri AB.

21. McKinlay J, Link C, Marceau L, O'Donnell A, Arber S, Adams A, et al. How do doctors in different countries manage the same patient? Results of a factorial experiment. Health Serv Res. 2006:41:2182-200.

22. Karlsson S, Hallberg IR, Midlöv P, Fagerström C. Trends in treatment with antipsychotic medication in relation to national directives, in people with dementia - a review of the Swedish context. BMC Psychiatry. 2017;14;17(1): 251. https://doi.org/10.1186/s12888-017-1409-9.

23. Edberg A-K, Gerdner LA, Buckwalter KC. Nurses guide for behavioural and psychological symptoms of dementia. BPSD Educational Package. Chicago: International (25) Psychogeriatric Association, IPA; 2007. http://docplayer. net/9858871-The-ipa-complete-guides-to-behavioral-and-psychologicalsymptoms-of-dementia-international-w-w-w-i-p-a-o-n-l-i-n-e-o-r-g-bpsd.html. Accessed 25 Jul 2018

24. Cancerplan (Eng: Cancerplan) 2016-2019, Regionalt cancercentrum StockholmGotland. Tillsammans för patienten hela vägen genom cancervården. (Eng: Regional Cancer Center Stockholm-Gotland. Together for the patient all the way through the chain of cancer care). (26) https://www.cancercentrum.se/ globalassets/vara-uppdrag/strategisk-utvecklingsplan/ stockholm\%2D\%2D-gotland/cancerplan-slutversion-22-jan.pdf. Accessed 25 Jul 2018.

25. Backhaus R, van Rossum E, Verbeek H, Halfens RJ, Tan FE, Capezuti E, et al. Relationship between the presence of baccalaureate-educated RNs and quality of care: a cross-sectional study in Dutch long-term care facilities. BMC Health Serv Res. 2017;19:17:53. https://doi.org/10.1186/s12913-0161947-8.

26. Traynor V, Inoue K, Crookes P. Literature review: understanding nursing competence in dementia care. J Clin Nurs. 2011;20:1948-60. https://doi.org/ 10.1111/j.1365-2702.2010.03511.x. Epub 2011 Mar 15.

27. Backhaus $R$, Verbeek $H$, van Rossum E, Capezuti E, Hamers JP. Future distinguishing competencies of baccalaureate-educated registered nurses in nursing homes. Geriatr Nurs. 2015;36:438-44. https://doi.org/10.1016/j. gerinurse.2015.06.012. Epub 2015 Aug 15.

28. Harrington C, Choiniere J, Goldmann M, Jacobsen FF, Lloyd L, McGregor M, et al. Nursing home staffing standards and staffing levels in six countries. J Nurs Scholarsh. 2012;88-98. https://doi.org/10.1111/j.1547-5069.2011.01430.x. Epub 2012 Feb 16.

29. World Medical Association (WMA). Declaration of Helsinki. Ethical principles for medical research involving human subjects. https://www.wma.net/ policies-post/wma-declaration-of-helsinki-ethical-principles-for-medicalresearch-involving-human-subjects/. Accessed 25 Jul 2018.

30. World Healthcare Organization (WHO). ATC/DDD Index 2018. https://www. whocc.no/atc_ddd_index/. Accessed 25 Jul 2018.

31. Kozman MN, Wattis J, Curran S. Pharmacological management of behavioural and psychological disturbance in dementia. Hum Psychopharmacol. 2006;21: $1-12$

32. World Healthcare Organization (WHO). Definition of Palliative Care. http:// www.who.int/cancer/palliative/definition/en/. Accessed 25 Jul 2018.

\section{Ready to submit your research? Choose BMC and benefit from:}

- fast, convenient online submission

- thorough peer review by experienced researchers in your field

- rapid publication on acceptance

- support for research data, including large and complex data types

- gold Open Access which fosters wider collaboration and increased citations

- maximum visibility for your research: over 100M website views per year

At BMC, research is always in progress.

Learn more biomedcentral.com/submissions 